\title{
Eficácia do glyphosate na dessecação de espécies de Urochloa ${ }^{1}$
}

\author{
Efficacy of glyphosate in the burndown of Urochloa species
}

\author{
Uadson Ramos da Silva ${ }^{2}$; Paulo César Timossi ${ }^{3}$; Dieimisson Paulo Almeida ${ }^{4}$; Suzete Fernandes \\ Lima $^{5}$
}

Resumo - Na operação de dessecação de plantas de cobertura do solo em áreas sob plantio direto o glyphosate é o herbicida mais utilizado. Com objetivo de determinar a susceptibilidade de plantas de cobertura ao glyphosate em operação de dessecação, três espécies do gênero Urochloa (Urochloa ruziziensis cv. Kennedy, U. decumbens cv. Basilisk e $U$. brizantha cv. BRS Piatã) e quatro doses de glyphosate $\left(0 ; 0,72,1,44\right.$ e 2,16 $\left.\mathrm{kg} \mathrm{ha}^{-1}\right)$ foram estudadas em esquema de parcelas subdivididas (3x4). As avaliações de eficácia da dessecação foram realizadas aos 7, 14, 21 e 28 dias após a aplicação (DAA), através de notas visuais (0 a 100\%). A $U$ ruziziensis foi eficientemente controlada aos 14 DAA de glyphosate na dose de $1,44 \mathrm{~kg} \mathrm{ha}^{-1}$, ou até os 28 DAA com $0,72 \mathrm{~kg} \mathrm{ha}^{-1}$. Glyphosate aplicado na dose de $2,16 \mathrm{~kg} \mathrm{ha}^{-1}$ não foi suficiente para controlar a $U$. decumbens até os 14 DAA, e assim como para $U$. brizantha até os 28 DAA. A velocidade de controle da cobertura vegetal formada por $U$. ruziziensis com glyphosate foi superior a $U$. decumbens e $U$. brizantha.

Palavras-chaves: capim-braquiária, plantio direto, herbicida

Abstract - In Burndown cover plants in areas under no-till the glyphosate herbicide is the most widely used. With the aims to determine the lower dose to burndown the cover crop species adopted the Urochloa ruziziensis cv. Kennedy, U. decumbens cv. Basilisk e U. brizantha cv. BRS Piatã, in four doses $\left(0,0,72,1,44\right.$ and $2,16 \mathrm{~kg} \mathrm{ha}^{-1}$ of acid equivalent). The experimental design was of randomized blocks with four replications, in a plot scheme subdivided ( $3 \times 4)$, in which the plots were set up by the species of Urochloa and subplots by doses of glyphosate. The U. ruziziensis was efficiently controlled the 14 DAA of glyphosate at $1.44 \mathrm{~kg} \mathrm{ha}^{-1}$, or up to 28 DAA with $0.72 \mathrm{~kg} \mathrm{ha}^{-1}$. Glyphosate applied at the rate of $2.16 \mathrm{~kg} \mathrm{ha}^{-1}$ was not sufficient to control the $U$. decumbens until $14 \mathrm{DAA}$, and until 28 DAA for $U$. Brizantha. The speed control of vegetation formed by $U$. ruziziensis with glyphosate was greater than $U$. decumbens and $U$. Brizantha.

Keywords: Brachiaria sp., no-till, herbicide

\footnotetext{
${ }^{1}$ Recebido para publicação em 09/09/2013 e aceito em 26/01/2014.

${ }^{2}$ Eng. Agr. Mestre em Agronomia - Analista de Desenvolvimento Rural na EMATER, Itarumã, GO. Rua Goiás, $n^{\circ}$ 24, Centro, 75810-000. Email: <Uadsonrs@ gmail.com>. (Autor para correspondência).

${ }^{3}$ Professor na Universidade Federal de Goiás - Câmpus Jataí. Rodovia BR 364, km 192, Setor Parque Industrial, 3800, Caixa postal 03, 75801-615, Jatai, GO, Brasil.

${ }^{4}$ Eng. Agr. Mestre em Agronomia. Rodovia BR 364, km 192, Setor Parque Industrial, 3800, Caixa postal 03, $75801-$ 615, Jatai, GO, Brasil.

${ }^{5}$ Eng. Agr. Mestre em Agronomia, Pesquisadora - Bolsista pela FUNAPE - na Universidade Federal de Goiás Câmpus Jataí. Rodovia BR 364, km 192, Setor Parque Industrial, 3800, Caixa postal 03, 75801-615, Jatai, GO, Brasil.
} 


\section{Introdução}

Para que a técnica de Plantio Direto seja eficaz na região do cerrado brasileiro é necessário seguir alguns precedentes como a formação e manejo da cobertura vegetal do solo no período de entressafra. Esta prática também se torna uma alternativa viável para a supressão da comunidade de plantas daninhas (Nunes et al., 2006; Severino et al., 2006; Ikeda et al., 2007; Timossi et al., 2007 e Noce et al., 2008), às quais podem evitar o aumento do denominado banco de sementes no solo (Pariz et al., 2009).

Além dos aspectos de formação da cobertura vegetal e seus benefícios para a proteção do solo, há que se considerar a ciclagem de nutrientes, supressão de plantas daninhas, além da facilidade no manejo químico antecedendo a semeadura da cultura de verão. Assim, a escolha da espécie formadora da palhada e o seu manejo químico assumem grande importância para o sucesso no emprego do Plantio Direto (Nunes et al., 2009).

O manejo químico das plantas de cobertura é realizado geralmente com os herbicidas glyphosate, sulfosate, diquat e paraquat (Kozlowski, 2001). Entretanto, o glyphosate tem sido o herbicida mais utilizado (Jaremtchuk et al., 2008). De acordo com Nepomuceno et al. (2012), diversas doses de glyphosate têm sido testadas para o controle de diferentes plantas de cobertura. Segundo Timossi et al. (2006), a dose de glyphosate na dessecação de plantas de cobertura pode variar de acordo com a espécie e estádio de desenvolvimento das mesmas.

Uma característica pouco explorada pela comunidade científica é a velocidade de controle da cobertura vegetal, algo almejado por agricultores que atuam em regiões onde se realiza duas safras ao ano. Neste contexto, espécies que são controladas eficientemente em menor tempo após a aplicação do herbicida se mostram mais adequadas, por proporcionar maior intervalo para o cultivo das culturas. Nunes et al. (2009), constataram que a
Urochloa decumbens apresentou bom controle na dessecação entre 7 e 14 dias após aplicação. Já Nepomuceno et al. (2012), verificaram que o período recomendado para o manejo químico de Urochloa ruziziensis com glyphosate foi de 10 a 20 dias antes da semeadura da soja.

Neste contexto, objetivou-se com o trabalho investigar a eficácia e velocidade de controle de doses de glyphosate na dessecação de espécies do gênero Urochloa.

\section{Material e Métodos}

A pesquisa foi realizada no campo experimental da Fazenda Escola Santa Rosa do Rochedo, pertencente à Universidade Federal de Goiás, Câmpus Jataí, localizada nas coordenadas de S $17^{\circ} 55^{\prime}$ 7,67', W $51^{\circ}$ 44'9,29" e altitude de $700 \mathrm{~m}$. O solo do local é caracterizado como Latossolo Vermelhodistroférrico, com relevo suave, boa drenagem e textura argilo-arenosa (Embrapa, 2006).

$\mathrm{O}$ delineamento experimental adotado foi de blocos casualizados, com quatro repetições e os tratamentos dispostos em esquema de parcelas subdivididas $3 \times 4$. As parcelas foram constituídas por três espécies de braquiária (Urochloa ruziziensis cv. Kennedy, Urochloa decumbens cv. Basilisk e Urochloa brizantha cv. BRS Piatã), com dimensões de $4,0 \times 40,0 \mathrm{~m}$ e, as subparcelas $(4,0 \times 10,0 \mathrm{~m})$, constituídas pelas dosagens do herbicida glyphosate a 0,$0 ; 0,72 ; 1,44$ e $2,16 \mathrm{~kg} \mathrm{ha}^{-1}$ de equivalente ácido (e.a.) adotadas para a dessecação.

As forrageiras foram semeadas manualmente a lanço no mês de março de 2012, com incorporação superficial por grade niveladora de arrasto, com ângulo fechado, visando à mínima interferência nas propriedades físicas do solo, além da disposição das sementes a até $0,05 \mathrm{~m}$ de profundidade, adotando 380 pontos de Valor Cultural (VC), de acordo com recomendações técnicas (Embrapa, 2001). Aos 230 DAS (dias após a semeadura), época na qual foi realizada a dessecação, coletou-se amostras das espécies 
de Urochloa para determinação de massa seca, por meio de lançamento aleatório de um quadro metálico sobre a parte aérea das plantas $(0,50 \times 0,50 \mathrm{~m})$. As amostras coletadas foram levadas à câmara de circulação forçada de ar a aproximadamente $65 \pm 5^{\circ} \mathrm{C}$, até que a massa das amostras não sofresse variações expressivas. Verificou-se que as braquiárias $U$. ruziziensis, $U$. decumbens e $U$. brizantha acumularam, respectivamente, 15,$2 ; 11,8 \mathrm{e}$ 15,0 Megagrama (Mg) ha ${ }^{-1}$ de massa seca.

Os dados climatológicos referentes ao período de condução da pesquisa (Figura 1) foram obtidos na estação agrometeorológica do
Instituto Nacional de Meteorologia (INMET), localizada a $1000 \mathrm{~m}$ da área experimental.

A aplicação do glyphosate foi realizada com pulverizador costal pressurizado a $\mathrm{CO}_{2}$ com pressão constante de $210 \mathrm{kPa}$, munido de barra com seis pontas jato plano DG 11002, espaçadas em $0,5 \mathrm{~m}$ e consumo de calda equivalente a $200 \mathrm{~L}^{-1}$. As condições atmosféricas iniciais e finais do local do experimento durante a aplicação dos tratamentos herbicida foram monitoradas com termo-higrômetro e anemômetro e avaliação visual da cobertura do céu por nuvens, às quais são apresentadas na Tabela 1.

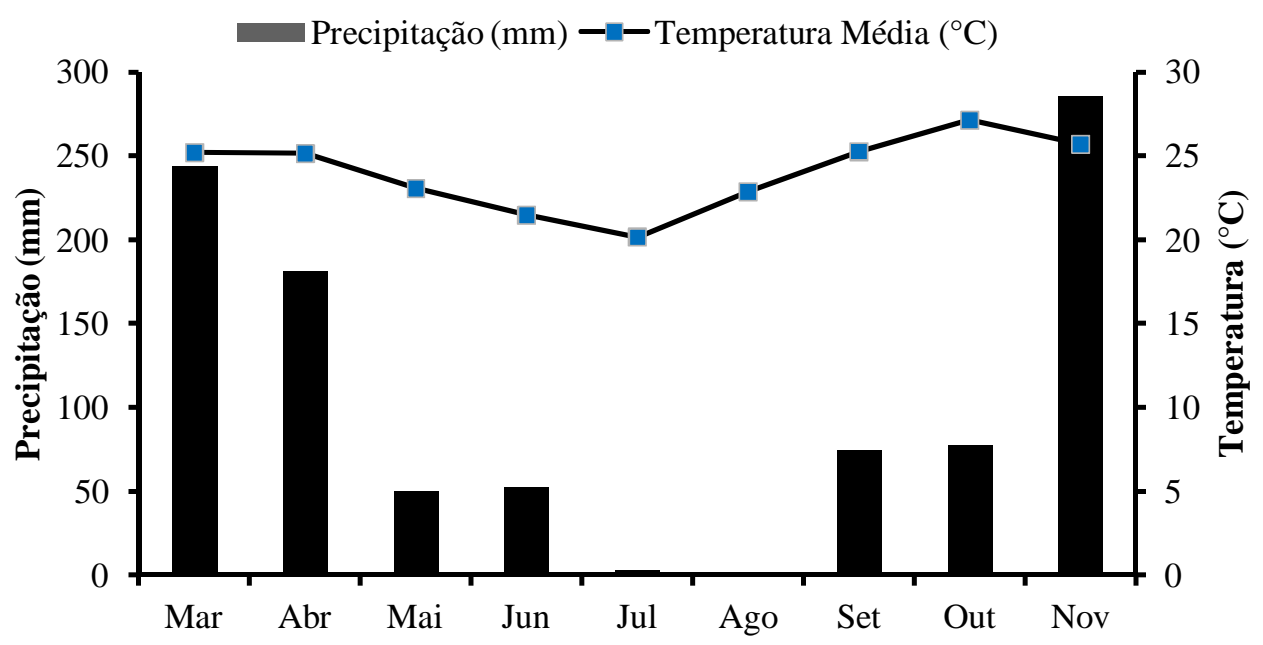

Figura 1. Temperatura média do ar e total de precipitações, em meses, durante o período de condução do experimento (Março a Novembro de 2012). INMET, 2012.

Tabela 1. Condições atmosféricas registradas no momento da aplicação dos tratamentos com as doses do herbicida glyphosate.

\begin{tabular}{|c|c|c|c|c|c|c|c|}
\hline \multicolumn{2}{|c|}{ Horário } & \multicolumn{2}{|c|}{ Temperatura } & \multicolumn{2}{|c|}{ Umidade } & \multirow{2}{*}{$\begin{array}{c}\text { Velocidade } \\
\text { média dos } \\
\text { ventos } \\
\end{array}$} & \multirow{2}{*}{$\begin{array}{l}\text { Cobertura do } \\
\text { céu por nuvens }\end{array}$} \\
\hline Inicial & Final & Inicial & Final & Inicial & Final & & \\
\hline $10: 50$ & $13: 15$ & $27,6^{\circ} \mathrm{C}$ & $28,8^{\circ} \mathrm{C}$ & $78 \%$ & $79 \%$ & $3-5 \mathrm{~km} \mathrm{~h}^{-1}$ & $98 \%$ \\
\hline
\end{tabular}

As avaliações de eficácia de dessecação pelas dosagens de glyphosate sobre as plantas de cobertura foram realizadas visualmente aos 7; 14; 21 e 28 dias após a aplicação (DAA), adotando-se porcentagem de controle dos vegetais de cobertura, atribuindo valores de 0 a $100 \%$, onde $0 \%$ foi atribuído a nenhum controle e $100 \%$ ao controle total da cobertura vegetal (Gazziero et al., 1995).

Os resultados obtidos foram submetidos a analise de variância, e para comparação de médias, adotou-se o teste de Tukey a $5 \%$ de probabilidade. 


\section{Resultados e Discussão}

Na Tabela 2 encontra-se representado o resumo das análises de variância (valores de F) dos resultados de eficácia de dessecação das coberturas do solo. Pode-se verificar que houve interação significativa entre as coberturas e as dosagens do herbicida glyphosate, em todas as épocas avaliadas.

Tabela 2. Resumo da análise de variância das médias obtidas na avaliação visual de controle das coberturas vegetais, em diferentes épocas e doses do herbicida glyphosate.

\begin{tabular}{|c|c|c|c|c|}
\hline \multirow{2}{*}{ Causa de variação } & \multicolumn{4}{|c|}{ Valor de F } \\
\hline & $7 \mathrm{DAA}^{1 /}$ & $14 \mathrm{DAA}$ & $21 \mathrm{DAA}$ & 28 DAA \\
\hline Coberturas (C) & $41,84 * *$ & $205,02 * *$ & $147,67 * *$ & $319,18^{* *}$ \\
\hline Dose do herbicida $(\mathrm{H})$ & $64,77 * *$ & $207,12 * *$ & $105,50 * *$ & $83,87 * *$ \\
\hline $\mathrm{C} \times \mathrm{H}$ & $3,25 *$ & $26,84 * *$ & $15,74 * *$ & $18,44 * *$ \\
\hline C.V (\%) parcela (C) & 21,3 & 6,6 & 6,6 & 4,0 \\
\hline C.V (\%) subparcela $(\mathrm{H})$ & 7,9 & 4,7 & 5,9 & 6,4 \\
\hline
\end{tabular}

"DAA - Dias após a aplicação; * significativo a $5 \%$ de probabilidade, ** significativo a $1 \%$ de probabilidade.

Em todas as épocas avaliadas a cobertura formada pela Urochloa ruziziensis cv. Kennedy foi controlada com maior eficácia em relação às outras espécies de Urochloa (Tabelas 3, 4, 5 e 6), exceto aos 21 e 28 DAA, nos quais na dose de $2,16 \mathrm{~kg} \mathrm{ha}^{-1}$ não há diferenças significativas entre a $U$. ruziziensis $\mathrm{e}$
$U$. decumbens. Entretanto, sabe-se que a adoção de dose elevada de um herbicida pode torná-la economicamente inviável no campo, assim como é indesejada a falta de controle eficaz da cobertura para operação de semeadura.

Tabela 3. Porcentagens de controle das coberturas vegetais aos 7 DAA de glyphosate.

\begin{tabular}{|c|c|c|c|}
\hline \multirow{2}{*}{ Dose de glyphosate } & \multicolumn{3}{|c|}{ Controle das coberturas vegetais $(\%)^{1 /}$} \\
\hline & U. ruziziensis & U. decumbens & U. brizantha \\
\hline $0,72 \mathrm{~kg} \mathrm{ha}^{-1}$ & $58,8 \mathrm{~A} \mathrm{~b}^{1 / 2}$ & $21,2 \mathrm{~B} \mathrm{~b}$ & 33,8 B b \\
\hline $1,44 \mathrm{~kg} \mathrm{ha}^{-1}$ & $72,5 \mathrm{~A} \mathrm{a}$ & $37,5 \mathrm{~B}$ a & $38,8 \mathrm{~B} \mathrm{ab}$ \\
\hline $2,16 \mathrm{~kg} \mathrm{ha}^{-1}$ & $76,2 \mathrm{~A} \mathrm{a}$ & $43,8 \mathrm{~B} \mathrm{a}$ & $45,0 \mathrm{~B} \mathrm{a}$ \\
\hline
\end{tabular}

DMS (5\%)

Herb. dentro de coberturas

Cob. dentro de herbicidas
6,78

13,05

${ }^{1 /}$ Médias seguidas de mesma letra maiúscula na linha e minúscula na coluna não diferem entre si, pelo teste de Tukey $(\mathrm{P}<0,05)$. DAA = dias após a aplicação.

Tabela 4. Porcentagens de controle das coberturas vegetais aos 14 DAA de glyphosate.

\begin{tabular}{|c|c|c|c|}
\hline \multirow{2}{*}{ Dose de glyphosate } & \multicolumn{3}{|c|}{ Controle das coberturas vegetais $(\%)^{1 /}$} \\
\hline & U. ruziziensis & U. decumbens & U. brizantha \\
\hline $0,72 \mathrm{~kg} \mathrm{ha}^{-1}$ & $86,2 \mathrm{~A} \mathrm{~b}^{1 /}$ & $40,0 \mathrm{~B} \mathrm{c}$ & $45,0 \mathrm{~B} \mathrm{c}$ \\
\hline $1,44 \mathrm{~kg} \mathrm{ha}^{-1}$ & 99,0 А а & $75,0 \mathrm{~B} \mathrm{~b}$ & $56,2 \mathrm{C} \mathrm{b}$ \\
\hline $2,16 \mathrm{~kg} \mathrm{ha}^{-1}$ & $100,0 \mathrm{~A} \mathrm{a}$ & $85,0 \mathrm{~B} \mathrm{a}$ & $68,8 \mathrm{C} \mathrm{a}$ \\
\hline
\end{tabular}

DMS (5\%)

Herb. dentro de coberturas

6,15

Cob. dentro de herbicidas

7,10

\footnotetext{
${ }^{T /}$ Médias seguidas de mesma letra maiúscula na linha e minúscula na coluna não diferem entre si, pelo teste de Tukey $(\mathrm{P}<0,05)$. DAA = dias após a aplicação.
} 
Tabela 5. Porcentagens de controle das coberturas vegetais aos 21 DAA de glyphosate.

\begin{tabular}{|c|c|c|c|}
\hline \multirow[t]{2}{*}{ Dose de glyphosate } & \multicolumn{3}{|c|}{ Controle das coberturas vegetais $(\%)^{1 /}$} \\
\hline & U. ruziziensis & U. decumbens & U. brizantha \\
\hline $0,72 \mathrm{~kg} \mathrm{ha}^{-1}$ & $88,7 \mathrm{~A} \mathrm{~b}^{1 /}$ & $47,5 \mathrm{~B} \mathrm{c}$ & $50,0 \mathrm{~B} \mathrm{c}$ \\
\hline $1,44 \mathrm{~kg} \mathrm{ha}^{-1}$ & $100,0 \mathrm{~A}$ a & $80,0 \mathrm{~B} \mathrm{~b}$ & $61,2 \mathrm{C} \mathrm{b}$ \\
\hline $2,16 \mathrm{~kg} \mathrm{ha}^{-1}$ & $100,0 \mathrm{~A} \mathrm{a}$ & $92,0 \mathrm{~A} \mathrm{a}$ & $72,5 \mathrm{~B}$ a \\
\hline \multicolumn{4}{|l|}{ DMS (5\%) } \\
\hline Herb. dentro de coberturas & & 8,15 & \\
\hline Cob. dentro de herbicidas & & 8,40 & \\
\hline
\end{tabular}

Tabela 6. Porcentagens de controle das coberturas vegetais aos 28 DAA de glyphosate

\begin{tabular}{ccccc}
\hline \multirow{2}{*}{ Dose de glyphosate } & \multicolumn{2}{c}{ Controle das coberturas vegetais $(\%)^{1 /}$} \\
\cline { 3 - 5 } & & U. ruziziensis & U. decumbens & U. brizantha \\
\hline $0,72 \mathrm{~kg} \mathrm{ha}^{-1}$ & $100,5 \mathrm{~A} \mathrm{a} \mathrm{a}^{1 /}$ & $52,5 \mathrm{~B} \mathrm{~b}$ & $50,0 \mathrm{~B} \mathrm{c}$ \\
$1,44 \mathrm{~kg} \mathrm{ha}^{-1}$ & $100,0 \mathrm{~A} \mathrm{a}$ & $89,5 \mathrm{~B} \mathrm{a}$ & $62,5 \mathrm{C} \mathrm{b}$ \\
$2,16 \mathrm{~kg} \mathrm{ha}^{-1}$ & $95,7 \mathrm{~A} \mathrm{a}$ & $81,2 \mathrm{~B} \mathrm{a}$ \\
\hline
\end{tabular}

DMS $(5 \%)$

Herb. dentro de coberturas $\quad 9,31$

$\begin{array}{lr}\text { Cob. dentro de herbicidas } & 8,17\end{array}$

${ }^{1 /}$ Médias seguidas de mesma letra maiúscula na linha e minúscula na coluna não diferem entre si, pelo teste de Tukey $(\mathrm{P}<0,05)$. DAA = dias após a aplicação.

Pesquisas realizadas por Santos et al. (2007), Nunes et al. (2009) e Nepomuceno et al. (2012) indicam que a época mais apropriada para a semeadura da cultura sucessora, a exemplo a cultura da soja, situa-se entre 7 e 21 dias após a dessecação, assim como para cultura do arroz que deve ser com mais de 10 dias (Nascente et al., 2012). Segundo Bergamin et al. (2013), o intervalo entre a dessecação e o cultivo da cultura em sucessão depende da espécie a ser escolhida e dose do herbicida a ser utilizada. Considerando a necessidade de ter a cobertura vegetal controlada na época indicada para semeadura da cultura seguinte, os resultados obtidos com a $U$. ruziziensis, dessecada com 1,44 $\mathrm{kg} \mathrm{ha}^{-1}$ de glyphosate
(Tabela 4 e 5), a condiciona como boa opção na formação de cobertura para o plantio direto no cerrado, em relação à $U$. decumbens e $U$. brizantha, as quais apresentaram controle inferior.

A maior rapidez no controle verificada com a U. ruziziensis é desejável por possibilitar a antecipação da semeadura da cultura após a dessecação, especialmente em áreas de cerrado brasileiro, onde são cultivadas duas safras no verão (safra e safrinha).

$\mathrm{Na}$ Figura 2 encontra-se representada uma caracterização visual da porcentagem de controle da massa vegetal das coberturas com o gênero Urochloa aos 14 DAA, utilizando a dose de $1,44 \mathrm{~kg} \mathrm{ha}^{-1}$ de glyphosate. 

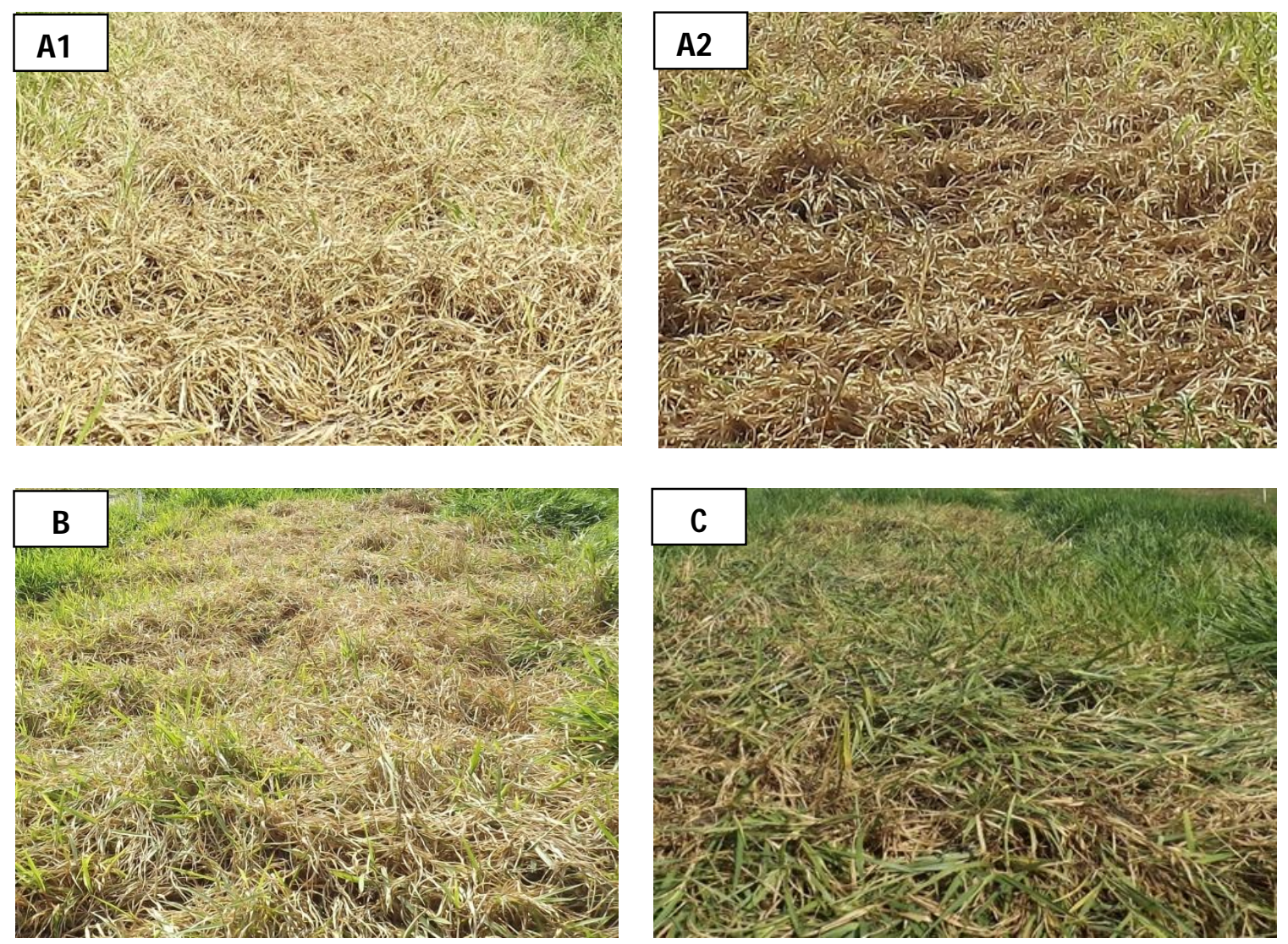

Figura 2. Eficácia de controle verificada na $U$. ruziziensis (A1 e A2), $U$. decumbens (B) e $U$. brizantha (C) aos 14 DAA, utilizando a dose de $1,44 \mathrm{~kg} \mathrm{ha}^{-1}$ de glyphosate.

Quando a dessecação não é realizada com eficácia pode provocar prejuízos à operação de semeadura, como 'embuchamento' e dificuldade de corte pelos discos da semeadora, o que pode provocar falhas no estande final da cultura (Greco \& Benez, 2003). Tal situação é agravada em regiões e situações onde não aguardam a morte total das coberturas (Figura 2-C), como a adotada no sistema aplique e plante, cuja finalidade é antecipar a semeadura e aumentar o rendimento operacional. Esse sistema pode interferir negativamente na taxa de emergência (Bergamin et al., 2013) e produtividade da soja (Oliveira Júnior et al., 2006; Constantin et al., 2009).

O nível de controle obtido (81\%) na cobertura formada pela $U$. brizantha cv. BRS Piatã não foi satisfatório, uma vez que para o sistema de semeadura direta procura se o controle total da vegetação de cobertura, a fim de facilitar a operação de semeadura e evitar reinfestações durante o estabelecimento da cultura subsequente. Em culturas geneticamente modificadas, como a tecnologia RR, por tolerar a aplicação de glyphosate tem esse problema amenizado a partir da aplicação sequencial, por meio de manejo complementar da reinfestação. Por outro lado, tal situação de manejo não seria possível em sistemas em que são adotadas culturas convencionais, ou seja, não tolerantes ao glyphosate.

\section{Conclusões}

A Urochloa ruziziensis cv. Kennedy foi eficientemente controlada aos 14 dias após a aplicação (DAA) de glyphosate na dose de $1,44 \mathrm{~kg} \mathrm{ha}^{-1}$, ou até os 28 DAA com $0,72 \mathrm{~kg}$ $\mathrm{ha}^{-1}$. 
Glyphosate aplicado na dose de $2,16 \mathrm{~kg}$ $\mathrm{ha}^{-1}$ não foi suficiente para controlar a Urochloa decumbens cv. Basilisk até os 14 DAA, assim como para Urochloa brizantha cv. BRS Piatã até os 28 DAA.

A velocidade de controle da cobertura vegetal formada por $U$. ruziziensis cv. Kennedy com glyphosate foi superior à $U$. decumbens cv. Basilisk e $U$. brizantha cv. BRS Piatã.

\section{Agradecimentos}

A CAPES e ao Programa de Pós Graduação em Agronomia da UFG/Câmpus Jataí, pela concessão da bolsa de mestrado.

\section{Referências}

BERGAMIN, A.C. et al. Manejo convencional do solo e Plantio Direto com diferentes intervalos de dessecação do milheto sobre o desenvolvimento inicial da soja. Planta Daninha, v.31, n.1, p.137-146, 2013.

CONSTANTIN, J. et al. Sistemas de manejo de plantas daninhas no desenvolvimento e na produtividade da soja. Bragantia, v.68, n.1, p.125-135, 2009.

EMBRAPA. Centro Nacional de Pesquisa de Solos. Sistema brasileiro de classificação de solos. 2. ed. Rio de Janeiro, 2006. 306 p.

EMBRAPA. Centro Nacional de Pesquisa em Gado de Corte. Gado de corte divulga: Requisitos básicos para boa formação e persistência de pastagens. Campo Grande, MS, ago. 2001, no 52 .

GAZZIERO, D.L.P.; VELINI, E.D. OSIPE, R. Procedimentos para instalação, avaliação e análise de experimentos com herbicidas. Londrina: Sociedade Brasileira da Ciência das Plantas Daninhas, 1995. 42p.

GREGO, C.R.; BENEZ, S.H. Manejo da cobertura vegetal do solo na implantação da cultura da soja (Glycine max (L.) Merril) semeada com dois mecanismos sulcadores. Energia Agrícola, v.18, n.3, p.48-52, 2003.
IKEDA, F.S. et al. Banco de sementes no solo em sistemas de cultivo lavoura-pastagem. Pesquisa Agropecuária Brasileira, v.42, n.11, p.1545-1551, 2007.

INMET - Instituto Nacional de Meteorologia. Estações automáticas: Jataí- Goiás, 2012.

JAREMTCHUK, C.C. et al. Efeito de sistemas de manejo sobre a velocidade de dessecação, infestação inicial de plantas daninhas e desenvolvimento e produtividade da soja. Acta Scientiarum Agronomy, v.30, n.4, p.449-455, 2008.

KOZLOWSKI, L.A. Aplicação sequencial de herbicidas de manejo na implantação da cultura do feijoeiro comum em sistema de plantio direto. Revista Brasileira de Herbicidas, v.2, n.1, p.49-56, 2001.

NASCENTE, A.S. et al. Brachiaria ruziziensis and herbicide on the yield of upland rice. Planta Daninha, v.30, n.4, p.729-736, 2012.

NEPOMUCENO, M.P. et al. Períodos de dessecação de Urochloa ruziziensis e seu reflexo na produtividade da soja RR. Planta Daninha, v.30, n.3, p.557-565, 2012.

NOCE, M.A. et al. Influência da palhada de gramíneas forrageiras sobre o desenvolvimento da planta de milho e das plantas daninhas. Revista Brasileira de Milho e Sorgo, v.7, n.3, p.265-278, 2008.

NUNES, A.S. et al. Épocas de manejo químico de Brachiaria decumbens antecedendo $\mathrm{o}$ Plantio Direto de soja. Planta Daninha, v.27, n.2, p.297-302, 2009.

NUNES, U.R. et al. Produção de palhada de plantas de cobertura e rendimento do feijão em plantio direto. Pesquisa Agropecuária Brasileira, v.41, n.6, p.943-948, 2006.

OLIVEIRA JR., R.S. et al. Interação entre sistemas de manejo e de controle de plantas daninhas em pós-emergência afetando $o$ desenvolvimento e a produtividade da soja. Planta Daninha, v.24, n.4, p.721-732, 2006. 
PARIZ, C.M. et al. Desempenhos técnicos e econômicos da consorciação de milho com forrageiras dos gêneros Panicum e Brachiaria em sistema de integração lavoura-pecuária. Pesquisa Agropecuária Tropical, v.39, n.4, p.360-370, 2009.

SANTOS, J.B. et al. Época de dessecação anterior à semeadura sobre o desenvolvimento da soja resistente ao glyphosate. Planta Daninha, v.25, n.4, p.869-875, 2007.

SEVERINO, F.J.; CARVALHO, S.J.P.; CHRISTOFFOLETI, P.J. Interferências mútuas entre a cultura do milho, espécies forrageiras e plantas daninhas em um sistema de consórcio. III - Implicações sobre as plantas daninhas. Planta Daninha, v.24, n.1, p.53-60, 2006.

TIMOSSI, P.C.; DURIGAN, J.C.; LEITE, G.J. Eficácia de glyphosate em plantas de cobertura. Planta Daninha, v.24, n.3, p.475-480, 2006.

TIMOSSI, P.C.; DURIGAN, J.C.; LEITE, G.J. Formação de palhada por braquiárias para adoção do sistema plantio direto. Bragantia, v.66, n.4, p.617-622, 2007. 